\title{
Recent Trends and Challenges in Human Resource Management
}

\author{
Anuradha Duvvuri \\ Research Scholar \\ GIET, Gunupur, Odisha
}

\begin{abstract}
This paper analyses the various challenges and the most recent trends that have evolved in the Human Resource department in the past few years. The functionality of HR managers shifted from recruitment process to a whole new significant role, which includes recruiting, selecting, retaining, training of employees. Along with this a HR manager is supposed to deal with motivation, welfare, perks, remuneration, infringements, and incentives of employees. This paradigm shift can be attributed to globalization that brought goals to be achieved by the HR department. The changes in HR department are phenomenal and the outlook of HRM has drastically changed. Personnel department to HRM, limited role of an HR executive to a varied role of HR executive, a limited scope of HRM to multidimensional scope of HRM there has been a sea change in the approach in the recent past. One more factor that revolutionized the HR department is technology which brought a positive impact. This radical change due to technology in HR department includes outsourcing, long-distance working model, overseas recruitment, flexible timing, and work from home option and so on. Globalization changed the scope of HRM and technology changed the functionality and approach of HRM. Because of the influence of globalization and technology HR department had to adapt to the changing times and so the scope of HRM has increased.
\end{abstract}

Keywords: Human Resource Management

\section{Introduction}

Human resource management is a process of setting common goals and bring organizations and people together. There has been a drastic change in the role of HR from a recruiter to the role of planner and change agent. According to Wendell French, "Human resource management is the systematic control of a network of interrelated process affecting and involving all members of an organization." HRM deals with recruitment, selection, training managing, developing, motivating, retaining employees, and does an important function of maintaining human rights in an organization. With time HRM has evolved to be an integral part of the organization. The role of the executive is to bind employees and an organization to bind employees for better and improved productivity. 21st century company brought better opportunities and along with-it enormous pressure on the HR executives with the onset of globalization, the demand for high skilled employees has increased multifold. So the HR executives should be well prepared for well-planned initiatives and a well-formulated mapping skills HR department has come to the forefront, with increased competition for the role of the HR department to help organizations be more resilient, adaptable, and agile. Daljeet Kaur Lal in his article-top trends in Human Resource Management in 2021 highlighted that "The trends of artificial intelligence, diversity, gig economy, cloud-based HR tech, and productivity skills will drive the HR management in 2021 to formulate, implement corporate strategies, and improve employee engagement to boost a business."

\section{Objectives}

1. To study the emerging trends in HRM

2. To understand the various challenges face by HR executive

3. To study the various techniques through which HR executive can overcome the challenges faced in this present business scenario 


\section{Research Methodology}

The research study is descriptive in nature. Data for the research paper is gathered from secondary data. The data are from a literature review, text books, and websites.

Need of the study: The purpose of the study is to analyse and understand the recent trends in HRM and also to understand the challenges face by the HR department in the field of HRM.

\section{Review of Literature}

Deepa Sharma in her Research paper "Analysis of Challenges Facing Human Resources Management" published in 2021, concluded that in the current scenario HR managers plays a pivotal role in the increased productivity of employees, organizational growth, and overall economic growth.

Khairi Mohamed Omar in his research paper "Key Elements of the HRM Challenges in the Technology Era 21st Century" published in 2021 highlighted that HR managers face a tough challenge and so a HR department should adapt to changing external and internal environment and introduce innovative recruitment policies which help to develop sound organizational structure.

Mrs. A. Mary Francina in her research paper "A Study on Trends and Challenges in Global HRM" in 2018 concluded that the HR department has to understand, revise the HR activities at the global perspective. The scholar concluded that HR executive should create organizational strategies to achieve competitive advantage.

Sandeep Kaur in his research paper "Recent trends in Human Resource Management" in 2017, mentioned that the reasons for the unprecedented growth of these new trends in the HR department can be because of globalization, liberalization, and technological advancement. It was concluded that along with the trends a new set of challenges also were to be faced by HR executives which can be retaining employees, dealing with cross cultural pool of employees.

Umadevi S Muttagi in her research paper "Recent Trends and Challenges in Human Resources Management in India" published in 2016 concluded that HR executive should be adaptable and quick in taking strategic decisions. HR executive can be effective if he manages through the various managerial functions like planning, organizing, controlling, and also a good knowledge about the recent trends in training and development.

\section{Result and Discussion}

From the present study it is interpreted that HRM has evolved over the years and had to adapt to new trends that has emerged in the recent past. In the data gathered it has been discussed about the various aspects that has added to the credentials of HRM and helped to interpret dimensions of the emerging trends. The following are some of the recent trends and challenges which are part of HRM.

\section{Current Trends in HRM}

\section{Encourage Diversity}

In today's organization set up, employees belong to diverse cultural backgrounds, sexual orientation, ages which put the onus on the HR department to encourage and instil confidence in the employees, and provide an atmosphere of equity and togetherness. This has a positive impact on the overall growth of the organization. Research shows that inclusive organizations have employee's performance increase by $50 \%$.

\section{Work from Home Option}

A recent trend that gained immense popularity and attention is work from home option. After the pandemic, organizations had a unique and novel approach of remote work to give flexible work hours. HR manager Stephanie Lane says that it "allows flexibility for employee scheduling, and it also expands the pool of talent which a company can hire from. "This move in fact has been the most successful from the point of view of HR department. It was observed that remote working reduced absenteeism and the employees are 
available online when needed. This option also encouraged many women who had restrictions to take up a career. The role of HR executive in remote working is to keep track of the employee performance and involvement. Post pandemic almost all organizations are offering work from home option as a full-time basis.

\section{Encourage Critical Thinking and Digital Skills}

The recent trend in HRM has seen that of upgrading the recruitment policy and to add to the criteria a very important requirement in a prospective candidate is that of critical thinking and digital skills. In today's tech-savvy corporate employees should be well versed with digital skills like data analytics. An HR executive also expects Critical thinking in the prospective candidates, which helps in conflict management and strategic thinking.

\section{Introduction of Re-skilling Internal Talent}

There always has been a worry for organizations to find skill gap in employees in today's fast-paced society a HR executive need to strategize to make sure there is skill development arranged to the employees by offering choices in careers, restructuring roles so that employees benefit from such an initiative. Upskilling existing employee's skill set is an important development in HRM.

\section{Implementing Artificial Intelligence (AI)}

Artificial Intelligence is a recent trend that gained a lot of momentum. It helps HR executive to use cloud computing in the recruitment process. With this technology HR executive can manage different functions easily and effectively. HR activities like payroll, employee training, managing performance of employees, verify employees resumes, reply to employees HR questions and so on data dissemination is well managed by AI. Deepti Chopra, Co-founder of Defaces "Companies that embraces AI will see a significant reduction in time-to-hire, and measurable improvement in the candidate experience.

\section{Flexible Working}

HR team should think of flexible working as a strategy to retain employees. In today's world or freelancing, retaining an employee's focus is difficult. This requires the HR executive to come out with a flexible work hour to suit the requirements of the varied needs of employees.

\section{Virtual Team Building}

Since employees are located in different geographical regions, traditional team building is next to impossible. Micheal Alexis CEO of Team Building says, "As more teams work from home, some organizations will figure out how to make [virtual team building] a long-term plan." Video call-based activities should be planned by the HR executive to build team building.

\section{Automation of Tasks}

Ralph Chapman, CEO of HR Search Pros, says "I have seen a huge uptick in the technology that people in HR use to become more efficient and effective over the last several years.". HR department is always burdened with a lot of paper work, so a new trend emerging is that of Automation of tasks like, payroll, recruitment, billing, employee evaluation, employee tax document.

\section{Strategies which are Data Driven}

HR department has to take many decisions every day, which may include, selecting candidates, choosing the best benefit plan, employee perks and so on. HR strategies should be based on analytics and using information effectively. The available information should be tracked and measured.

\section{New Modes of Training}

Training and development are a core competency of the HR department. A well-planned training session always the employees to improve skills, gain knowledge and improve performance. The recent trends in HRM training session have been virtual learning session, collaborative learning, conference sessions, hands on experience hands on experience to the employees 


\section{Emphasising on Learning}

HR executives should emphasize on employees upgrading their skills. This can be done by providing employees with an annual stipend, paid time off and paid leave allotment. According to Clodgah Beaty, Cocreator of the Emotional Salary Barometer says, "While the professional growth and development will continue to be important, we anticipate an increase in personal growth initiatives. The importance of personal growth in leadership development and the focus on the purpose and meaning at work will continue."

\section{Renewed Employee Experience}

Since organizations have a hybrid model of work where employees choose between virtual and traditional workspace, it is the responsibility of the HR executive to balance this hybrid model with diligence. This requires the HR executive improve online virtual process, better communication combined with technological solutions, new and innovative compensation packages.

\section{Social Safety}

In the recent years, the social safety net has become part of an organization. This includes the HR executive to bring in an innovative policy to support employees and community welfare. The support activities include financial assistance, enhanced sick leave, flexible work hours, community relief fund, and free community services.

\section{Recruitment Marketing}

Instead of traditional marketing, recruitment marketing involves HR executives using social media, blogs, and other platforms to attract candidates. This requires coordination between HR and marketing department. The scope of HRM has become multi-fold, bringing along a lot of challenges like employee well-being, safety at the workplace, employee grievances, technological upgradation, and new techniques of recruitment.

\section{Challenges Faced by HRM}

HRM in recent years has gained a lot more complexities with unique challenges coming their way. Irrespective, of the size of the company and its geographical location every company has some challenges that are robust. HR challenges emerge because of economic, political, climatic, and social situations. A smart HR manager should always make sure that resources of the organization are spent judiciously with an effort to make sure employees have the required resources for high productivity levels.

The scope of HRM has become multi-fold, bringing along a lot of challenges like employee wellbeing, safety at the workplace, employee grievances, technological upgradation, new techniques of recruitment wile maintain productivity of employees. Some of the challenges are highlighted below:

\section{Attraction and Retention of Employees}

A daunting task on the HR department in the recent past was about attracting new talent into the organization and retaining the employees. HR executives should focus to check whether employees fit in the organization based on the job description. This challenge of attracting new talent can be addressed by HR executive through building reward system of referrals to encourage employees to introduce new people. HR executive can also introduce techniques like collaboration, transparent leadership to attract fresh talent.

Another challenge of the HR department is retaining talented employees, since a high turnover rate may become a financial pressure on the company. This challenge can be overcome by the HR department a favourable work environment, better opportunities to employees and motivation, recognition, and engagement of employees.

\section{Accepting Change}


HR department faces a challenge of change in the external and internal environment. Such changes and challenges can be political, technological, and social. HR mangers should embrace and accept change and prepare the employees about the same. Embracing change by HRM can be through transparent communication with employees, understand, and strategize future requirements of the organization.

\section{Continuous Learning Process}

A challenge usually faced by HR department is that of upskilling employee's skill set. A robust task of HR executive is to review, monitor the employee's performance, find deviations, and take corrective action. So, this challenge of skill improvement and development can be introduced by the HR executive through setting learning goals and introducing online leaning, micro-learning.

\section{Managing A Diverse Team}

One of the challenges faced by HR executive is that of managing employees with diverse backgrounds, ideas, experiences. This challenge can be faced by building an inclusive team and introducing cultural awareness activities, team building activities, celebrate cultural diversity and so on.

\section{Controlling Turnover Rate}

HRM faces the challenge of employee turnover. It is a tough task to a HR manager to reduce turnover rates which may increase the cost and impact the use of resources. This challenge can be tackled by the HR executive through techniques like training and development to upskill employee's skill set, flexible work hours, conducting exit interviews and so on.

\section{Globalization}

A very recent challenge that the HR department is Globalization has to deal with a diverse workforce. It might be difficult to have the effect virtually on an employee. However, there is software that can help you build a work culture online. So, the HR managers have to find ways to leverage this challenge like better management accepting diverse cultures and languages.

\section{Complying with the Rules and Regulation}

HR professional usually struggle to keep a track of laws and regulations applicable to the company. So, not complying to the policies may affect the growth of the company and may also waste the resources as this may

\section{Productivity}

High employee productivity has become a new business expectation in today's corporate world. So, HR managers need to manage and maintain high employee productivity needs and consistent procedures and make sure that employee performance is being monitored and their issues are being addressed. High productivity can be maintained with right tools, improve skills of employees through training and development.

\section{Technology}

A recent challenge that HR managers face is that of technology. New methods of working, cloud computing, new apps, digital platforms are some of the challenges that HR managers need to update. HR managers can face this challenge by updating the and upgrading the company and having a strong technical team to help the company adapt to new technological trends.

\section{Understanding Generation Z:}

Today's HR department has to learn to work to a millennial generation which has a new work style, a different outlook and a different attitude. So, HR managers need to accommodate to the expectation of this generation and make sure the policies are framed keeping in mind the current scenario.

\section{How to Overcome these Challenges}

- Proper planning 
- Transparent recruitment and selection process

- Ethical HR policies

- Understanding and complying to different provisions

- Proper communication

- Coordination between departments

- Proper interpretation of objectives

- Updating HR policies according to changing external and internal environment

\section{Result and Conclusion}

From the viewpoint of the above explanation, it is clear that HRM faces varied challenges, like work force diversity, globalization, adapting to new trends, training and development. These challenges can be overcome through employee motivation, technological upgradation and involvement of new trends like Artificial Intelligence, automation of work and so on. Today's HRM, has to rise to the expectations of the management, employees, and aspiring job seekers and create a competitive edge. HR executives should interpret the top management policies and execute them in a broad perspective and should align with organizational goals. HR executives should vouch for innovation, which is a new mantra for organizational success. HRM role shifted from recruitment alone to recruiting and retaining fresh talent. The role of HRM has become multi-dimensional, which includes change management, tackling diverse workforce, globalization, technological upgradation, planning, and so on. HR department needs to be efficient and effective to face the competitors and also manage to face risk and uncertainty. HRM should be well prepared and strategically approach the challenges and risks. It can be concluded that HRM as a department evolved in the recent past. Contribution of this department has undoubtedly helped the company to transit and to face the challenges frequently faced by the organization.

\section{Limitations}

There have been certain limitations during the process of research study. To mention a few:

- Since the research paper is based on secondary data, it was difficult gather information from various sources.

- Since the research was framed to identify "trends" some trends were overlooked as they were repeated.

- The data collected has been from various websites and it was not easily available and time consuming.

- There was also an inability to detect relevant changes that happened.

\section{References}

[1] http://www.villanovau.com/resources/hr/human-resource-management

[2] Argyris C., Schon D. (1977) Organizational learning: A theory of Action Perspective. Addison-Wesley, Reading, MA

[3] Anderson S. E., Coffey B. S., Byerly R. T. (2002) Formal organizational initiatives \& informal workplace practices: Links to work-family conflict and job-related outcomes. Journal of Management. 28 (6). 787-810

[4] Andersen K. K., Cooper B. K., Zhu C. J. (2007) The effect of SHRM practices on perceived financial performance: some initial evidence from Australia. Asia Pacific Journal of Human Resources, Vol. 45 